\title{
A case-control study of $B R C A 1$ founder mutations 185delAG and 5382insC in a cohort of Egyptian ovarian cancer patients using pyrosequencing technique
}

\author{
Mohamed M. Rizk ${ }^{1}$, Nour M. El-etreby ${ }^{2}$, Lama M. El-Attar ${ }^{3}$, Eman A. Elzyat ${ }^{1}$ and Marwa H. Saied ${ }^{1 *}$ (1)
}

\begin{abstract}
Background: Ovarian cancer $(\mathrm{OC})$ is considered a leading cause of death among women with gynecological malignancies. OC, like breast cancer, shows a familial predisposition to germline mutations in genes BRCA1 or BRCA2, which have proved to play important roles in the incidence and progression of cancers. In Arab countries there are limited data concerning BRCA1 or BRCA2 founder mutations associated with familial ovarian cancer (FOC). Therefore, the aim of this pilot study was to assess two common founder mutations of BRCA1 (185delAG and 5382insC) in a cohort of Egyptian patients with FOC. The study included fifty female patients with FOC and twenty healthy controls. Clinical, laboratory, and pathological findings were assessed as well as response to therapy. Genetic testing for BRCA1 (185delAG and 5382insC) mutations was performed on peripheral blood samples using a short-fragment sequencer (pyrosequencer).

Results: The BRCA1 185delAG mutation was not observed in either the FOC patients or the controls. However, the carrier frequency of heterozygous BRCA1 5382insC mutation was 8\%. All the FOC patients with a BRCA1 5382ins C mutation had a positive family history of cancer $(p=0.009)$. All carriers of the BRCA1 5382insC mutation showed a preliminary good response to chemotherapy. The majority of carrier patients were diagnosed at an advanced stage of the disease with high-grade tumors and distant metastasis (75\% of cases).
\end{abstract}

Conclusion: The frequency of the BRCA1 5382insC mutation in FOC patients was $8 \%$. The strong association between the mutation and the positive family history suggests that a wider screening for BRCA1 founder mutations would be valuable in predicting high-risk individuals.

Keywords: Familial ovarian cancer, BRCA1 gene, BRCA2 gene, Founder mutation, Pyrosequencing

\section{Background}

Among the most common gynecological malignancies, ovarian cancer $(\mathrm{OC})$ ranks third after cervical cancer and uterine cancer. OC has a poor prognosis and a fatal outcome in those affected. The main reason for the high

\footnotetext{
*Correspondence: marwahanafi@yahoo.co.uk

${ }^{1}$ Department of Clinical and Chemical Pathology, Faculty of Medicine, Alexandria University, Champlion Street, El-Khartoum Square, The Medical Campus, Alexandria, Egypt

Full list of author information is available at the end of the article
}

mortality rate in $\mathrm{OC}$ is due to the fact that in the early stages, most patients are asymptomatic or have non-specific symptoms. The silent spread of OC in conjunction with the lack of satisfactory screening tests mean that advanced, widespread disease often occurs before diagnosis $[1,2]$.

The exact cause of familial ovarian cancer (FOC) is not well understood and may be attributed to genetic factors, environmental or lifestyle factors, or it may occur by chance $[3,4]$. It has been found that $8-15 \%$ of OC patients have germline mutations of the BRCA genes 
(BRCA1 and BRCA2) and this is considered as one of the underlying causes of FOC $[5,6]$.

BRCA 1 and 2 are tumor suppressor genes that play an important role in DNA repair and the maintenance of chromosomal stability through homologous recombination (HR). Any change in the nucleotide sequence of either BRCA 1 or BRCA 2 genes results in loss of heterozygosity, genome instability, and an increased risk of malignancy, usually as OC or breast cancer (BC) [7-9].

There are three common germline founder mutations implicated in FOC. Two founder mutations are found in the BRCA1 gene (185delAG and 5382insC), and one founder mutation in the BRCA2 gene (BRCA2 6174delT) [8].

Both BRCA1 185delAG and BRCA1 5382insC founder mutations are frameshift mutations that result in truncated non-functioning proteins. In the case of the BRCA1 $185 \mathrm{del} A$ mutation, there is a deletion of adenine and guanine at position 185 of exon 2 of the BRCA1 gene [10]. With the BRCA1 5382insC mutation, there is an insertion of a cytosine nucleotide at position 5382 of exon 20.

The BRCA1 5382insC mutation originated in northern areas of Russia and spread to Ashkenazi Jews and other populations in Eastern Europe [11, 12]. Previous studies investigated the frequency of those mutations using different techniques. BRCA1 185delAG was studied using duplex/multiplex-PCR [13], while the 5382insC mutation was detected by ARMS-based PCR [14]. Both studies were performed in Eastern India [13, 14].

However, there are a lack of reports regarding the carrier frequency of BRCA1 founder mutations in the Middle East and Africa. A recent study done by Ashour and Ezzat Shafik [15] on 104 epithelial OC patients of different ancestries (61.54\% of patients were of Arabic origin) revealed 21 pathogenic variants in 22 patients of Arabic and Asian origins. This study was done through sequencing the translational exons of BRCA 1and 2 and the immediately adjacent introns.

The increased use of germline genetic testing in patients with $\mathrm{OC}$ or $\mathrm{BC}$ has had a significant effect on cancer care [16] because the presence of BRCA1 or BRCA2 mutations can alter the management of OC patients to involve, for example, targeted therapy with Poly (ADP-ribose) polymerase (PARP) inhibitors [17].

The traditional Sanger sequencing is relatively expensive compared to the short-fragment sequencer (pyrosequencer) [18]. The use of the cost-effective method of pyrosequencing in detecting point mutations has a great significance in determining mutation carriers, whether in patients or at-risk relatives. Consequently, the purpose of our work was to detect two well-known BRCA1 founder mutations: 185 delAG and 5382insC in Egyptian females with FOC using a pyrosequencer.

\section{Methods}

\section{Patients}

Seventy females were enrolled in the present study. Fifty FOC patients were recruited from the inpatient and outpatient clinics of the oncology department during the period from June 2017 to June 2018. Twenty healthy, age-matched females with a negative family history were enrolled as controls. All patients signed a written, informed consent, and the study was approved by the local ethics committee. The study protocol was in agreement with the Declaration of Helsinki guidelines1975, as revised in 2000.

Females who participated in the study were selected by having one or more of the following inclusion criteria:

1. A first-degree relative (mother, sister, or daughter) or second-degree relative who has ovarian, colorectal, or breast cancer.

2. A personal history of breast cancer before age 40 years.

3. A personal history of breast cancer diagnosed before age 50 years, and/or one or more relatives (first or second degree) who have breast cancer or ovarian cancer or both.

Any patient diagnosed with OC only and without personal or reported family history was excluded. Data were collected for age, menstruation, marital status, parity, and family history of breast, ovarian, and colorectal cancer. A full clinical examination was done.

Radiological investigations including ultrasonography examination and computed tomography $(\mathrm{CT})$ of the abdomen and pelvis were done at the time of diagnosis in conjunction with routine laboratory investigations. Tumor markers as carbohydrate antigens (CA 125, CA 19.9, and CEA) and histopathological examination after definitive surgical procedure, tumor stage, and metastasis were extracted from the medical records of each patient.

\section{Mutation analysis \\ DNA extraction}

For mutation detection, DNA extraction was done using a QIAamp Blood Mini Kit (catalog no.51104). DNA concentration and quality were assessed by a NanoDrop spectrophotometer (NanoDrop ND-2000, ThermoScientific, USA).

\section{PCR amplification of target regions}

PCR amplification of target regions was done using a Pyromark PCR kit (catalog number: 978703, Qiagen). The sequence of oligonucleotide primers flanking the mutation loci were used as described: [10] BRCA1 185de1AG forward: $\quad 5^{\prime}$-AAGTTGTCATTTTATAAACCTT-3' 
reverse: 5'-TGTCTTTTCTTCCCTAGTATGT-3'biotin, sequencing primer $5^{\prime}$-TGACTTACCAGATGGGA-3' BRCA1 5382insC forward: 5'-AAAGCGAGCAAGAGA ATCCC-3', reverse $5^{\prime}$-TGGGGTGAGATTTTTGTC AAC-3biotin, sequencing primer: $5^{\prime}$-CGAGCAAGAGAA TCCC-3'

The PCR reaction mix was as follows: $12.5 \mu \mathrm{l}$ of PyroMark PCR Master Mix (2X), $1 \mu \mathrm{l}$ of each forward and reverse primer $(10 \mu \mathrm{mol}), 2.5 \mu \mathrm{l}$ Coral Load Concentrate (10X), $5.5 \mu \mathrm{l}$ RNase-free water and $2.5 \mu \mathrm{l}$ Template DNA. The PyroMark PCR Master Mix contains HotStarTaq DNA Polymerase and optimized PyroMark PCR Buffer (includes $3 \mathrm{mM} \mathrm{MgCl} 2$ and dNTPs). PCR was performed using Thermo Scientific Arktik Thermal Cycler PCR Machine (Arktik thermocycler, ThermoScientific, USA). The thermal cycling conditions started with an initial activation for $15 \mathrm{~min}$ at $95^{\circ} \mathrm{C}$ then for BRCA1 185delAG: 50 cycles of denaturation for $30 \mathrm{~s}$ at $94{ }^{\circ} \mathrm{C}$, annealing for $30 \mathrm{~s}$ at $52{ }^{\circ} \mathrm{C}$, and extension for $30 \mathrm{~s}$ at $72{ }^{\circ} \mathrm{C}$. For BRCA1 5382insC the amplification was done for 45 cycles with annealing temperature at $55^{\circ} \mathrm{C}$ for $30 \mathrm{~s}$. The final extension step for both mutations was for $10 \mathrm{~min}$ at $72{ }^{\circ} \mathrm{C}$.

\section{Pyrosequencing}

Before running the pyrosequencer, it is necessary to confirm the presence of a single clear PCR product over the gel. Therefore, PCR amplicons were checked over $2 \%$ agarose gel electrophoresis; a band sized $72 \mathrm{bp}$ was detected in BRCA1 5382insC, while in BRCA1 185delAG, the product band size was $80 \mathrm{bp}$ (Fig. 1). Pyrosequencing was then performed using Qiagen Pyromark Q24 GOLD kit (Catalog No. 970802), Samples were loaded on a PyroMark Q24 following the manufacturer's instructions.

Briefly, pyrosequencing is based on hybridization of the sequencing primer to a single-stranded PCR-amplified DNA template. The template is incubated with enzymes and substrates that are supplied in the pyrosequencing kit. During sequencing, the four nucleotides [adenine $(\mathrm{A})$, thymine $(\mathrm{T})$, cytosine $(\mathrm{C})$, guanine $(\mathrm{G})]$ are added sequentially. If a nucleotide is complementary to a base in the template strand, it will be incorporated into a DNA strand by a polymerase enzyme. Each incorporation event is accompanied by release of pyrophosphate (PPi). ATP sulfurylase converts PPi to ATP in the presence of adenosine 5' phosphosulfate. This drives the conversion of luciferin to oxyluciferin by luciferase enzyme, generating a visible light in amounts proportional to the amount of ATP. Light is detected using charged coupled devices (CCDs) and seen as a peak.

Internal controls were obtained by negative insertion of nucleotide dispensations. Analysis of the results was done by PyroMark Q24 software in the form of a pyrogram for each sample, where peak heights are proportional to the

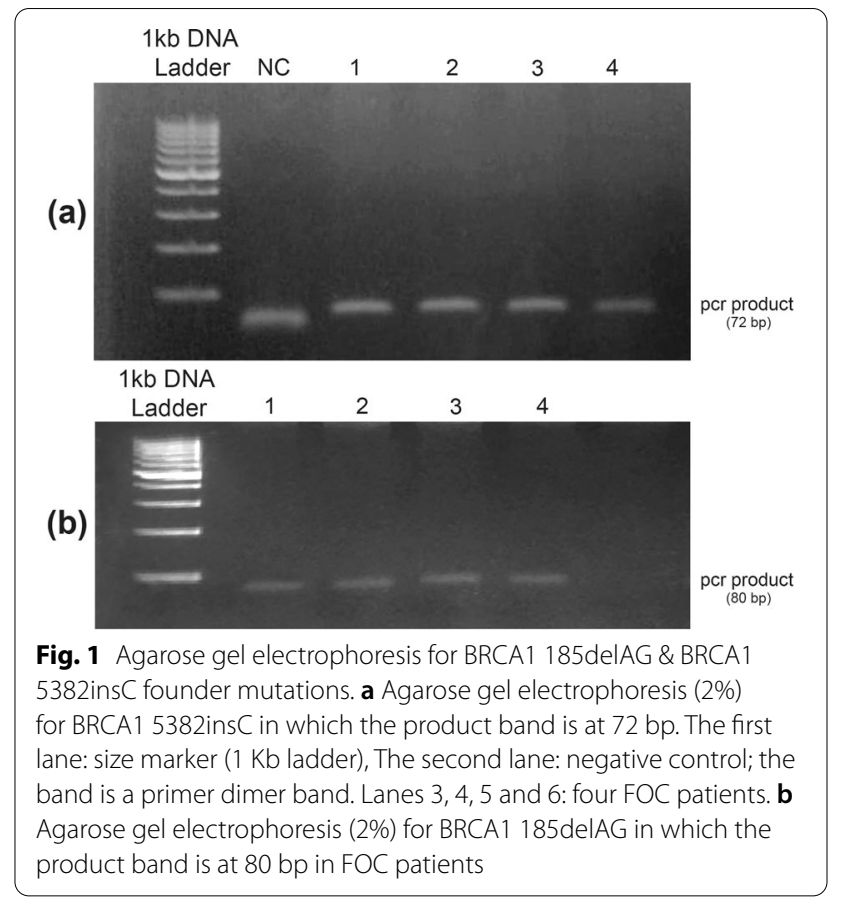

nucleotides' numbers that are incorporated with each dispensation. For BRCA1 185delAG, the intensities of C and $\mathrm{T}$ peaks were approximately half of those in the wildtype internal controls, indicating a deletion of $\mathrm{CT}$ in one allele. While for the BRCA1 5382insC mutation, incorporation of an extra $C$ was present.

Data were fed to the computer and analyzed using a Graphic PAD Prism software package version 6.0. Qualitative data were described using numbers and percentages. Quantitative data were described by the mean and standard deviation. Chi-square test, Fisher's exact test, or Monte Carlo correction were used to compare between the carrier and non-carrier groups. Student $t$ test was used for normally distributed quantitative variables and Mann Whitney test for abnormally distributed quantitative variables. P-values less than 0.05 were considered statistically significant.

\section{Results}

The mean age of FOC patients included in the study was $50.08 \pm 14.56$ years. Comparing FOC patients and controls revealed no significant difference in age (Additional file 1: Table S1). Pyrosequencing of the DNA samples of FOC patients and controls revealed the absence of either heterozygous or homozygous BRCA1 185delA mutations (Fig. 2).

On the other hand, as Fig. 2 shows, heterozygous BRCA1 5382insC mutation was found in 4 out of 50 FOC patients with a carrier frequency of $8 \%$ (95\% CI 2.2-19.2). 


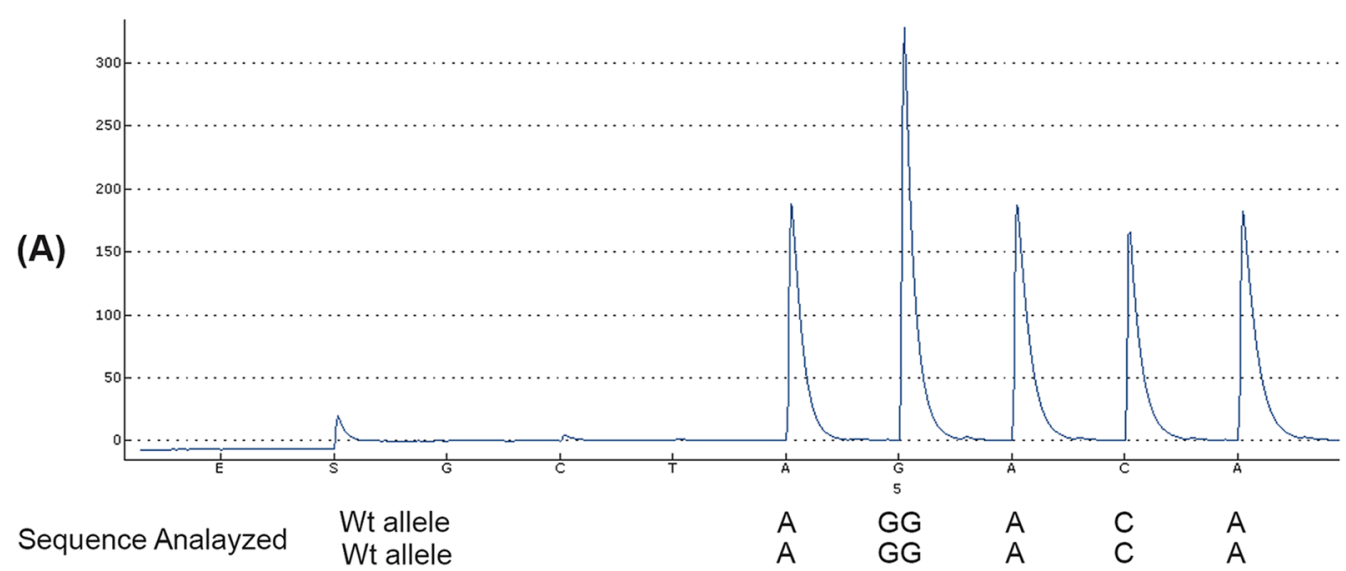

Pyrogram for wild type sequence for BRCA1 5382 insC.

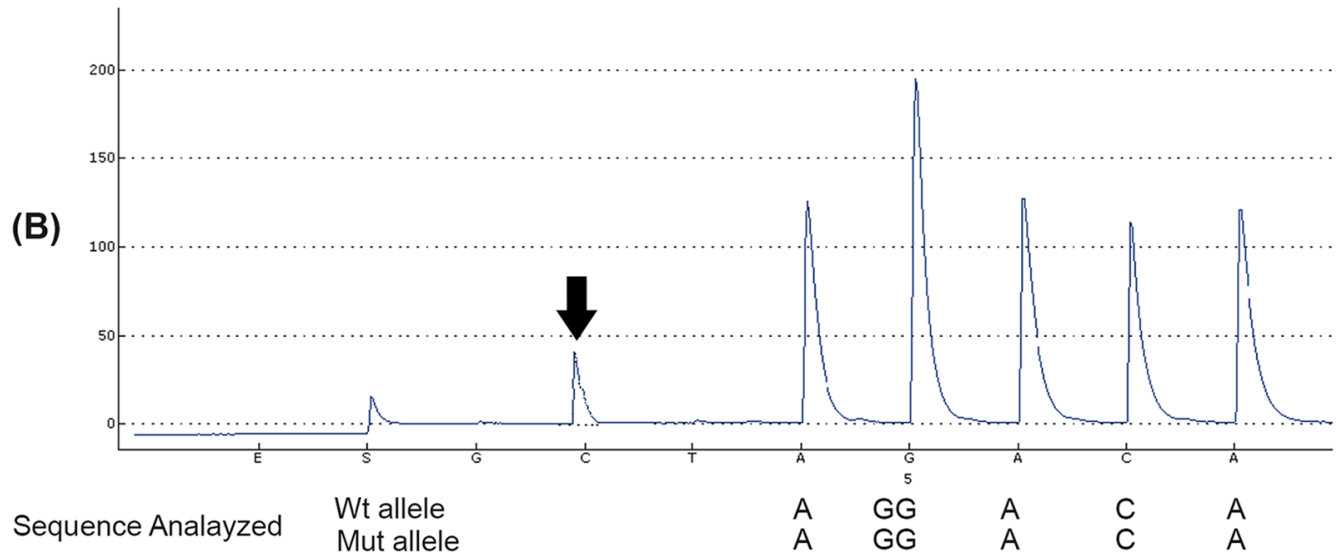

Pyrogram for heterozygous BRCA1 5382 insC mutation.

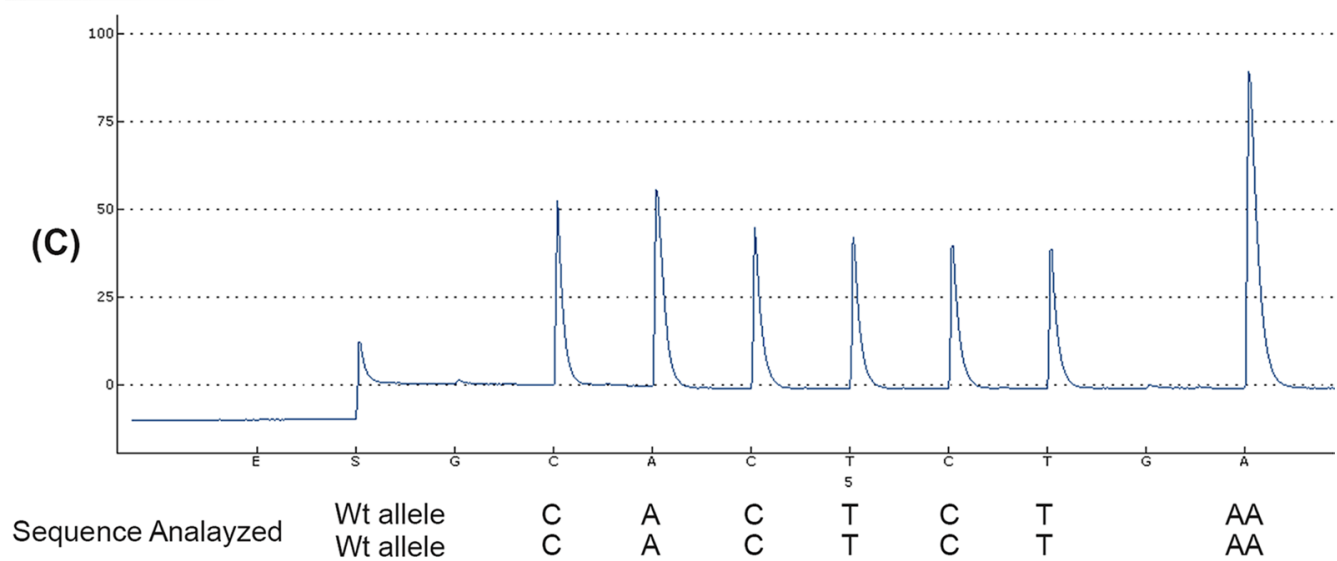

Pyrogram for wild type sequence for BRCA1185delAG.

Fig. 2 Representative pyrogram for BRCA1 185delAG and BRCA1 5382 insC founder mutation. A, B Pyrogram for wild-type sequence for BRCA1 5382 insC. B Pyrogram for heterozygous BRCA1 5382 insC mutation in a carrier FOC patient (case number 1). At position 2 there is an insertion of extra C. Negative internal controls were obtained by negative nucleotide dispensation of G unit at position 1 and T unit at position 3 . C At the wild-type sequence for BRCA1 185delAG, the generated peak heights for nucleotide dispensations at positions 2, 3, 4, 5, 6, and 7 (CACTCT in the reverse strand) are approximately equivalent and represent incorporation of a single nucleotide in both alleles (2 light units), but the signal intensity of A at position 9 is two times greater (4 light units) and reflects the incorporation of two as in tandem in both alleles 
However, BRCA1 5382insC mutation was not detected among the controls. Demographic and clinical characteristics of BRCA1 5382insC mutation in carrier patients are summarized in Table 1.

According to the presence of heterozygous BRCA1 5382insC, the FOC patients were further divided into two subgroups: carriers and non-carriers. The mean age of carriers was 48.25 years, and for noncarriers it was 56.50 years. Histopathological examination showed papillary serous invasive carcinoma in most of the FOC patients in the present study (44\%): $45 \%$ of noncarriers and 25\% of carriers (Additional file 1: Table S2). For the most part, OC was diagnosed in advanced stages; $60.9 \%$ of non-carriers and $75 \%$ of carriers were stage IIIIV. High-grade tumors (G 3) were manifested in both groups. The difference between carriers and non-carriers regarding cancer stage, grade, or metastasis was not significant ( $p=0.421, p=1.000$, and $p=0.14$ respectively) (Additional file 1: Tables S3 and S4). In addition, Additional file 1: Table S5 shows that the difference between carriers and non-carriers concerning the three measured tumor markers (CA125, CA19.9, and CEA) was not significant ( $p=0.174, p=0.508$, and $p=0.844$ respectively).

As Table 2 shows, there was no significant difference among the FOC subgroups regarding marital status, parity, and menopause. However, all carriers (100\%) had at least one first-degree relative affected by cancer (OC, BC, or colon cancer) with a significant difference between both carriers and non-carriers $(p=0.009)$. A pedigree of the carriers' families is demonstrated in Fig. 3.
Table 2 Comparison between BRCA1 5382insC carriers and non-carriers

\begin{tabular}{|c|c|c|c|c|c|}
\hline \multirow[t]{3}{*}{ Characteristic } & \multicolumn{4}{|c|}{ FOC patients } & \multirow[t]{3}{*}{ FEp } \\
\hline & \multicolumn{2}{|c|}{$\begin{array}{l}\text { Non-carrier } \\
(n=46)\end{array}$} & \multicolumn{2}{|c|}{ Carrier $(n=4)$} & \\
\hline & No & $\%$ & No & $\%$ & \\
\hline \multicolumn{6}{|l|}{ Marital status } \\
\hline Not married & 4 & 8.7 & 0 & 0.0 & 1.000 \\
\hline Married & 42 & 91.3 & 4 & 100.0 & \\
\hline \multicolumn{6}{|l|}{ State of menopause } \\
\hline Premenopausal & 13 & 28.3 & 1 & 25.0 & 1.000 \\
\hline Menopausal & 33 & 71.7 & 3 & 75.0 & \\
\hline \multicolumn{6}{|l|}{ Parity } \\
\hline Nullipara & 5 & 10.9 & 1 & 25.0 & 0.563 \\
\hline Unipara & 3 & 6.5 & 0 & 0.0 & \\
\hline Multipara & 38 & 82.6 & 3 & 75.0 & \\
\hline Affected family members & 39 & 84.8 & 4 & 100 & $0.009^{*}$ \\
\hline One & 35 & 76.1 & 1 & 25.0 & \\
\hline Two & 4 & 8.7 & 2 & 50.0 & \\
\hline Three & 0 & 0.0 & 1 & 25.0 & \\
\hline \multicolumn{6}{|l|}{ Response to chemotherapy } \\
\hline Good & 20 & 43.5 & 4 & 100.0 & $0.046^{*}$ \\
\hline No response & 26 & 56.5 & 0 & 0.0 & \\
\hline \multicolumn{6}{|l|}{ Survival } \\
\hline Died & 1 & 2.2 & 0 & 0.0 & 1.000 \\
\hline Survived & 45 & 97.8 & 4 & 100.0 & \\
\hline
\end{tabular}

$\mathrm{FE}$, Fisher's exact test

*Statistically significant at $p \leq 0.05$

Table 1 Demographic and clinicopathological characteristics of BRCA1 5382insC carrier patients

\begin{tabular}{|c|c|c|c|c|}
\hline & Carrier 1 & Carrier 2 & Carrier 3 & Carrier4 \\
\hline Age & 43 & 52 & 48 & 50 \\
\hline Age of first presentation & 40 & 50 & 45 & 48 \\
\hline Menopausal status & Premenopausal & Menopausal & Menopausal & Menopausal \\
\hline Parity status & Five & Four & Zero & Three \\
\hline Pathology & Metastatic undifferentiated carcinoma & $\begin{array}{l}\text { Invasive papillary } \\
\text { mucinous cystadenocar- } \\
\text { cinoma }\end{array}$ & $\begin{array}{l}\text { Invasive papillary serous } \\
\text { adenocarcinoma }\end{array}$ & Endometrioid carcinoma \\
\hline Stage & IV & IV & IV & । \\
\hline Grade & 3 & 3 & 3 & 1 \\
\hline Family history & $\begin{array}{l}\text { Personal history of neglected breast } \\
\text { lobular carcinoma, aunt (OC), } 2 \text { sisters } \\
\text { (BC) }\end{array}$ & Her aunt (Colon cancer) & 2 brothers had colon cancer & Sister $(B C)$, cousin $(O C)$ \\
\hline Bone metastasis & Positive & Free & Free & Free \\
\hline Visceral metastasis & Positive(liver) & Positive(liver) & Positive(liver) & Free \\
\hline Survivability & Still alive & Still alive & Still alive & Still alive \\
\hline Response to chemotherapy & Respond & Respond & Respond & Respond \\
\hline
\end{tabular}

$\mathrm{BC}$, breast cancer; OC, ovarian cancer; $\mathrm{MAC}$, metastatic undifferentiated carcinoma; $\mathrm{PSCC}$, papillary serous adenocarcinoma; PMCAC, papillary mucinous cystadenocarcinoma; EC, endometrioid carcinoma 


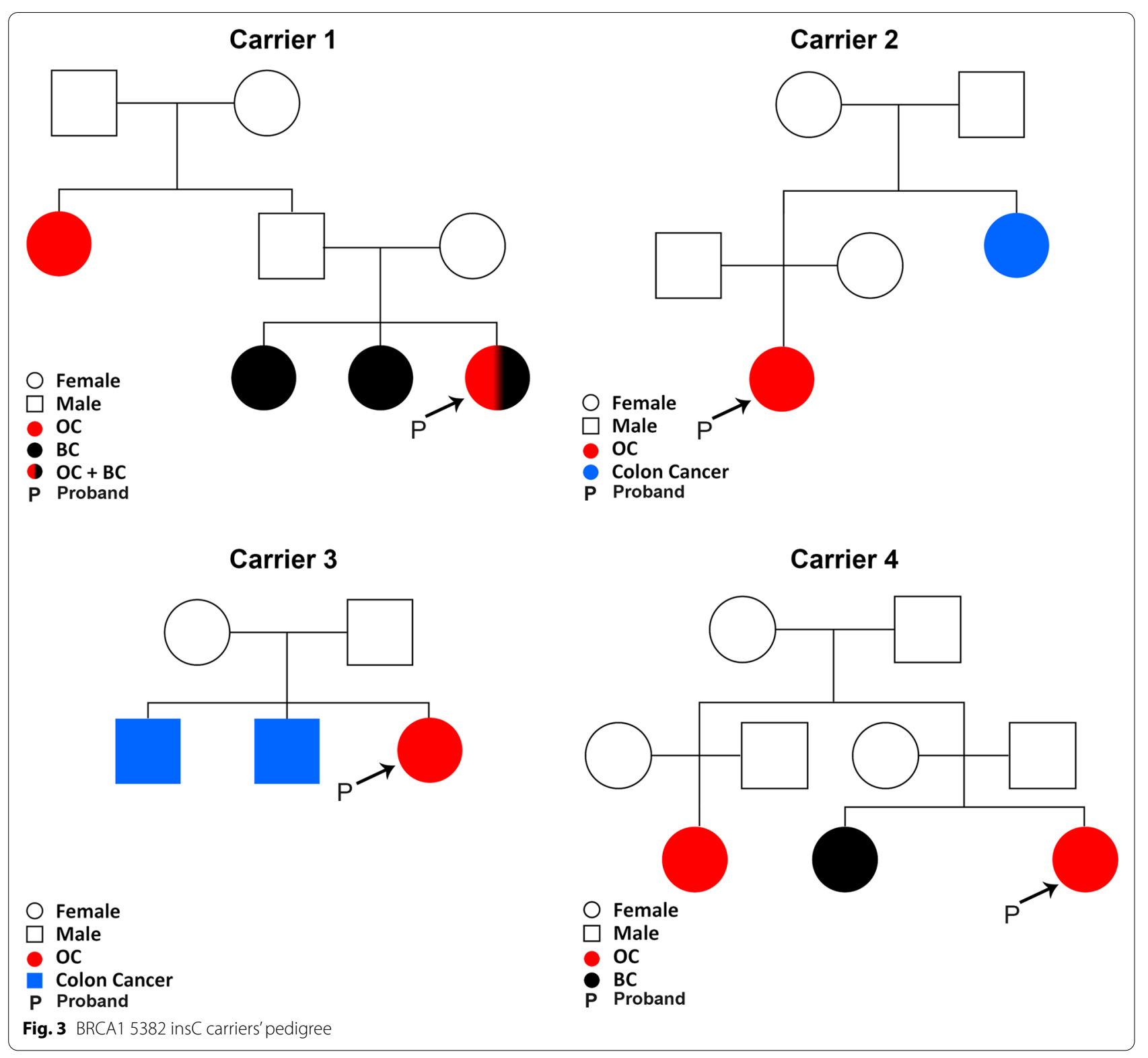

With regard to the response to platinum-taxane chemotherapy among 46 non-mutation/non-carrier patients, twenty had a preliminary good response to chemotherapy, while all mutation/carrier patients showed a good response (Table 2).

\section{Discussion}

$\mathrm{OC}$ is a worldwide gynecological malignancy. Although it is less common than $\mathrm{BC}$, its importance comes from the occult nature of its spread leading to late diagnosis and poor prognosis. The 5 -year survival rate is estimated to be approximately $30 \%$ in advanced stages [19].
The current study aimed to detect two common BRCA1 founder mutations (185delAG and 5382insC) to assess the carrier frequency in a cohort of Egyptian females with FOC using the pyrosequencing technique.

Heterozygous BRCA1 5382insC mutation was found in 4 out of 50 FOC patients enrolled in the current study with a carrier frequency of $8 \%$. This was within the previously reported range of $5-15 \%$ [20]. Synoweic et al. [21] reported BRCA1 5382insC mutation in 9.6\% of Polish FOC patients. Additionally, Moslehi et al. [22] found a frequency of $6.7 \%$ in Ashkenazi Jewish patients. Some discrepancy in the frequency of BRCA1 5382insC 
mutation carriers has been found among different populations, and it seems to be affected by ethnicity, study design, and methods of detection.

On the other hand, we did not find either heterozygous or homozygous BRCA1 185delAG, mutations among the FOC patients. Again, the frequency of the BRCA1 185delAG mutation is variable among different populations; a low carrier frequency of $1.1 \%$ was reported in Morocco [23], while a higher carrier frequency of $16.4 \%$ was found in India [24].

The main significant finding regarding the BRCA1 5382insC mutation in our study was the strong association with the history of cancer in at least one first-degree relative, particularly breast, ovarian, or colon cancer ( $100 \%$ in carriers vs. $84.8 \%$ in non-carriers; $p=0.009$ ). This issue could be explained by the fact that germline mutations of BRCA1 pass through an autosomal dominant pattern during familial aggregation $[22,25,26]$. The strong association between a family history of $\mathrm{OC}$ and/ or $\mathrm{BC}$ in first-degree relatives and BRCA1 founder mutation highlights the importance of screening for BRCA mutations in high-risk families in order to provide proper genetic counseling and prophylactic management such as salpingo-oophorectomy, which may reduce the risk of developing OC by $90 \%[27$, 28].

Also in the present study, the 4 BRCA1 5382insC mutation carriers showed a preliminary good response to chemotherapy. Many studies showed BRCA1 mutation carriers had a better response to chemotherapy and prognosis than non-carriers [29-31], while several studies found no significant difference between carriers and non-carriers regarding the chemotherapeutic response [25]. BRCA mutations enhance the DNA damaging effect of chemotherapeutic agents such as platinum, causing an increase in platinum sensitivity, which makes it the cornerstone of the initial regimen of treatment in such cases. This can be explained by it impairing the DNA repair mechanism of mutated cells, so they remain susceptible to damage by cytotoxic drugs [29]. However, platinum resistance may occur in some BRCA1 mutation carriers and results in poor prognosis and/or disease recurrence. In those patients, a shift to alternative drugs such as PARP inhibitors might be valuable [32, 33].

Intracellular PARP1 and PARP 2 enzymes play a crucial role in DNA repair mechanisms. Inhibition of such enzymes by PARP inhibitors leads to the accumulation of single-stranded DNA breaks and impaired DNA repair mechanisms with subsequent cytotoxicity and enhanced apoptotic effect [34].

The age of onset and tumor histopathology stage were also compared between carrier and non-carrier patients. It was observed that BRCA1 5382insC mutation was associated with advanced-stage, high-grade OC tumors and evident metastasis in $75 \%$ of enrolled patients. However, the small sample size rendered this association insignificant.

Overall, despite good facilities for diagnosis and management, there are no adequate data on the prevalence of BRCA1 germline mutations in Arab women with FOC; this is in addition to insufficient research on the underlying genetic mechanisms of OC and its familial aggregation. Based on the literature review, we can claim that the current study is the first in Egypt to apply screening for BRCA1 founder mutations in FOC patients using the pyrosequencing technique. Pyrosequencing is characterized by its high accuracy to pick up single nucleotide changes in short DNA fragments. Furthermore, uncomplicated automation in comparison with other methods, along with its reasonable cost, renders it more accessible for predicting disease outcome and high-risk individuals $[35,36]$.

\section{Conclusion}

The frequency of BRCA1 5382insC mutation in a cohort of Egyptian FOC patients was 8\%. There was a strong association between family history of HBOCrelated tumors and BRCA1 mutations. Moreover, all BRCA1 5382insC mutation carriers showed a preliminary good response to chemotherapy. Therefore, screening for BRCA1 5382insC mutation is valuable for the prevention of $\mathrm{OC}$ and for offering appropriate genetic counseling to high-risk families. A large-scale follow-up study with an expanded screening panel of BRCA mutations including those that have been recently recognized in Arabic patients [15] is highly recommended to assess the underlying molecular mechanisms.

\section{Abbreviations}

AST: Aspartate aminotransferase; BC: Breast cancer; BRCA1: Breast cancer1 gene; BRCA2: Breast cancer 2 gene; FOC: Familial ovarian cancer; HBOC: Hereditary breast ovarian cancer syndrome; OC: Ovarian cancer; PARP: Poly ADP ribose polymerase inhibitors.

\section{Supplementary Information}

The online version contains supplementary material available at https://doi. org/10.1186/s43042-022-00226-8.

Additional file 1: Comparison between BRCA1 5382insC carriers and non-carriers according to different laboratory data.

\section{Acknowledgements}

We are thankful to all patients who participated in this study. We also thank the Medical Research Center (MRC), Faculty of Medicine, Alexandria University for providing the pyrosequencing services. 


\section{Authors' contributions}

MMR conceived and designed the study. NME, LME, EME, and MHS did the practical work, statistical analysis of the data, and writing the manuscript. All authors read and approved the final manuscript.

\section{Funding}

No funding was received for this study.

\section{Availability of data and materials}

The datasets used and/or analyzed during the current study are available from the corresponding author on reasonable request.

\section{Declarations}

\section{Ethics approval and consent to participate}

All patients signed a written informed consent, and the study was approved by the local ethics committee of Faculty of Medicine, Alexandria University, Egypt. The study protocol was in agreement with the Declaration of Helsinki guidelines 1975, as revised in 2000. The reference number is not applicable.

\section{Consent for publication}

Not applicable.

\section{Competing interests}

The authors declare no conflicts of interest.

\section{Author details}

${ }^{1}$ Department of Clinical and Chemical Pathology, Faculty of Medicine, Alexandria University, Champlion Street, El-Khartoum Square, The Medical Campus, Alexandria, Egypt. ${ }^{2}$ Department of Obstetrics and Gynecology, Faculty of Medicine, Alexandria University, Alexandria, Egypt. ${ }^{3}$ Department of Human Genetics, Medical Research Institute, Alexandria University, Alexandria, Egypt.

Received: 14 July 2021 Accepted: 21 November 2021

Published online: 26 January 2022

\section{References}

1. Goff BA, Mandel LS, Melancon CH, Muntz HG (2004) Frequency of symptoms of ovarian cancer in women presenting to primary care clinics. JAMA 291(22):2705-2712. https://doi.org/10.1001/jama.291.22.2705

2. Bray F, Ferlay J, Soerjomataram I, Siegel RL, Torre LA, Jemal A (2018) Global cancer statistics 2018: GLOBOCAN estimates of incidence and mortality worldwide for 36 cancers in 185 countries. CA Cancer J Clin 68(6):394424. https://doi.org/10.3322/caac.21492.Erratum.In:CACancerJClin.2020J $u l ; 70(4): 313$

3. Ponder BAJ (1996) Familial ovarian cancer. In: Eeles et al. (ed) Genetic predisposition to cancer, Springer, Boston, pp 290-296. https://doi.org/ 10.1007/978-1-4899-4501-3_19

4. Elit L (2001) Familial ovarian cancer. Can Fam Phys 47:778-784

5. Rodríguez AO, Llacuachaqui M, Pardo GG, Royer R, Larson G, Weitzel JN, Narod SA (2012) BRCA1 and BRCA2 mutations among ovarian cancer patients from Colombia. Gynecol Oncol 124(2):236-243. https://doi.org/ 10.1016/j.ygyno.2011.10.027

6. Vietri MT, Caliendo G, D'Elia G, Resse M, Casamassimi A, Minucci PB, Dello Ioio C, Cioffi M, Molinari AM (2020) Five Italian families with two mutations in BRCA genes. Genes (Basel) 11(12):1451. https://doi.org/10.3390/ genes11121451

7. Tutt A, Ashworth A (2002) The relationship between the roles of BRCA genes in DNA repair and cancer predisposition. Trends Mol Med 8(12):571-576. https://doi.org/10.1016/s1471-4914(02)02434-6

8. Prat J, Ribé A, Gallardo A (2005) Hereditary ovarian cancer. Hum Pathol 36(8):861-870. https://doi.org/10.1016/j.humpath.2005.06.006

9. Floquet A, Stoeckle E, Croce S et al (2014) Les formes héréditaires du cancer de l'ovaire: particularités clinico-biologiques et thérapeutiques [Hereditary ovarian carcinomas: clinico-biological features and treatment]. Bull Cancer 101(2):167-174. https://doi.org/10.1684/bdc.2014. 1888
10. Zhang L, KirchhoffT, Yee CJ, Offit K (2009) A rapid and reliable test for BRCA1 and BRCA2 founder mutation analysis in paraffin tissue using pyrosequencing. J Mol Diagn 11(3):176-181. https://doi.org/10.2353/ jmoldx.2009.080137

11. Struewing JP, Abeliovich D, Peretz T, Avishai N, Kaback MM, Collins FS, Brody LC (1995) The carrier frequency of the BRCA1 185delAG mutation is approximately 1 percent in Ashkenazi Jewish individuals. Nat Genet 11(2):198-200. https://doi.org/10.1038/ng1095-198.Erratum.In:NatGe net1996Jan;12(1):110

12. Hamel N, Feng BJ, Foretova L, Stoppa-Lyonnet D, Narod SA, Imyanitov E et al (2011) On the origin and diffusion of BRCA1c 5266dupC (5382insC) in European populations. Eur J Hum Genet 19:300-306. https://doi.org/ 10.1038/ejhg.2010.203

13. Chakraborty A, Banerjee D, Basak J, Mukhopadhyay A (2015) Absence of 185delAG and 6174delT mutations among breast cancer patients of Eastern India. Asian Pac J Cancer Prev APJCP 16(17):7929-7933

14. Chakraborty A, Mukhopadhyay A, Bhattacharyya D, Bose CK, Choudhuri K, Mukhopadhyay S et al (2013) Frequency of 5382insC mutation of BRCA1 gene among breast cancer patients: an experience from Eastern India. Fam Cancer 12(3):489-495

15. Ashour M, Ezzat SH (2019) Frequency of germline mutations in BRCA1 and BRCA2 in ovarian cancer patients and their effect on treatment outcome. Cancer Manag Res 11:6275-6284

16. Domchek SM (2020) Germline genetic testing for breast cancer: which patients? What genes? Genet Med 22(4):698-700

17. Weil MK, Chen AP (2011) PARP inhibitor treatment in ovarian and breast cancer. Curr Probl Cancer 35(1):7-50

18. Simner PJ, Khare R, Wengenack NL (2015) Chapter 95-rapidly growing mycobacteria. In: Tang Y-W, Sussman M, Liu D, Poxton I, Schwartzman J (eds) Molecular medical microbiology, 2nd edn. Academic Press, Boston, pp 1679-1690

19. Saito T, Katabuchi H (2016) Annual report of the committee on gynecologic oncology, Japan Society of Obstetrics and Gynecology: patient annual report for 2013 and treatment annual report for 2008. J Obstet Gynaecol Res 42(9):1069-1079. https://doi.org/10.1111/jog.13043

20. Zhang S, Royer R, Li S, McLaughlin JR, Rosen B, Risch HA et al (2011) Frequencies of BRCA1 and BRCA2 mutations among 1,342 unselected patients with invasive ovarian cancer. Gynecol Oncol 121(2):353-357. https://doi.org/10.1016/j.ygyno.2011.01.020

21. Synowiec A, Wcisło G, Bodnar L, Górski B, Szenajch J, Szarlej-Wcisło K, Szczylik C (2016) Clinical features and outcomes of germline mutation BRCA1-linked versus sporadic ovarian cancer patients. Hered Cancer Clin Pract 8(14):1. https://doi.org/10.1186/s13053-015-0044-z

22. Moslehi R, Chu W, Karlan B, Fishman D, Risch H, Fields A, Smotkin D, Ben-David Y, Rosenblatt J, Russo D, Schwartz P, Tung N, Warner E, Rosen B, Friedman J, Brunet JS, Narod SA (2000) BRCA1 and BRCA2 mutation analysis of 208 Ashkenazi Jewish women with ovarian cancer. Am J Hum Genet 66(4):1259-1272. https://doi.org/10.1086/302853

23. Bar-Sade RB, Kruglikova A, Modan B, Gak E, Hirsh-Yechezkel G, Theodor L et al (1998) The 185delAG BRCA1 mutation originated before the dispersion of Jews in the diaspora and is not limited to Ashkenazim. Hum Mol Genet 7(5):801-805. https://doi.org/10.1093/hmg/7.5.801

24. Sirisha P, Vottery R, Amidyala L, Nallari P, Jyothy A et al (2017) Screening of BRCA 1-185delAG mutation in Ovarian Cancer patients in aTertiary care centre from Telangana. Gynecol Obstet (Sunnyvale) 7:444. https://doi. org/10.4172/2161-0932.1000444

25. Shi T, Wang P, Tang W, Jiang R, Yin S, Shi D, Wang Q, Wei Q, Zang R (2018) Survival benefit of germline BRCA mutation is associated with residual disease in ovarian cancer. Cell Physiol Biochem 47:2088-2096. https://doi. org/10.1159/000491477

26. Singer CF, Tan YY, Muhr D, Rappaport C, Gschwantler-Kaulich D, Grimm C, Polterauer S, Pfeiler G, Berger A, Tea MM (2019) Association between family history, mutation locations, and prevalence of BRCA1 or 2 mutations in ovarian cancer patients. Cancer Med 8(4):1875-1881. https://doi.org/10. 1002/cam4.2000

27. Liu JF, Konstantinopoulos PA, Matulonis UA (2014) PARP inhibitors in ovarian cancer: current status and future promise. Gynecol Oncol 133(2):362369. https://doi.org/10.1016/j.ygyno.2014.02.039

28. van Driel CM, de Bock GH, Arts HJ, Sie AS, Hollema H, Oosterwijk JC, Mourits MJ (2015) Stopping ovarian cancer screening in BRCA1/2 mutation carriers: effects on risk management decisions \& outcome of 
risk-reducing salpingo-oophorectomy specimens. Maturitas 80(3):318322. https://doi.org/10.1016/j.maturitas.2014.12.009

29. Tan DS, Rothermundt C, Thomas K, Bancroft E, Eeles R, Shanley S, ArdernJones A, Norman A, Kaye SB, Gore ME (2008) "BRCAness" syndrome in ovarian cancer: a case-control study describing the clinical features and outcome of patients with epithelial ovarian cancer associated with BRCA1 and BRCA2 mutations. J Clin Oncol 26(34):5530-5536. https://doi. org/10.1200/JCO.2008.16.1703

30. Vencken PMLH, Kriege M, Hoogwerf D, Beugelink S, van der Burg MEL, Hooning MJ et al (2011) Chemosensitivity and outcome of BRCA1- and BRCA2-associated ovarian cancer patients after first-line chemotherapy compared with sporadic ovarian cancer patients. Ann Oncol 22(6):13461352. https://doi.org/10.1093/annonc/mdq628

31. Loizzi V, Cicinelli E, Santamaria F, Murgia F, Minicucci V, Resta L, Resta N, Natalicchio MI, Ranieri G, Cormio G (2018) BRCAmut and "founder effect": a prospective study in a single academic institution. Oncotarget 9(32):22353-22358. https://doi.org/10.18632/oncotarget.24959

32. Farmer H, McCabe N, Lord CJ, Tutt AN, Johnson DA, Richardson TB, Santarosa M, Dillon KJ, Hickson I, Knights C, Martin NM, Jackson SP, Smith GC, Ashworth A (2005) Targeting the DNA repair defect in BRCA mutant cells as a therapeutic strategy. Nature 434(7035):917-921. https://doi.org/10. 1038/nature03445

33. Murai J, Huang SN, Das BB, Renaud A, Zhang Y, Doroshow JH, Ji J, Takeda S, Pommier Y (2012) Trapping of PARP1 and PARP2 by Clinical PARP Inhibitors. Cancer Res 72(21):5588-5599. https://doi.org/10.1158/0008-5472. CAN-12-2753

34. Ström CE, Johansson F, Uhlén M, Szigyarto CA, Erixon K, Helleday T (2011) Poly (ADP-ribose) polymerase (PARP) is not involved in base excision repair but PARP inhibition traps a single-strand intermediate. Nucl Acids Res 39(8):3166-3175. https://doi.org/10.1093/nar/gkq1241

35. Li AJ, Madden AC, Cass I, Leuchter RS, Lagasse LD, Karlan BY (2004) The prognostic significance of thrombocytosis in epithelial ovarian carcinoma. Gynecol Oncol 92:211-214

36. Ronaghi M (2001) Pyrosequencing sheds light on DNA sequencing. Genome Res 11(1):3-11. https://doi.org/10.1101/gr.11.1.3

\section{Publisher's Note}

Springer Nature remains neutral with regard to jurisdictional claims in published maps and institutional affiliations.

\section{Submit your manuscript to a SpringerOpen ${ }^{\circ}$ journal and benefit from:}

- Convenient online submission

- Rigorous peer review

- Open access: articles freely available online

- High visibility within the field

- Retaining the copyright to your article 